\title{
Information and communication technologies in the development of women's professional activity
}

\author{
Elena Polishchuk*, Natalia Stakhno, and Olga Pochupailo \\ V.I. Vernadsky Crimean Federal University, 95007 Simferopol, Russia
}

\begin{abstract}
The study describes the role of information and communication technologies (ICT), which have an impact on the development of professional activity of women. It is established that the problem of gender inequality is relevant because of the significant changes in modern society, in particular the rethinking of the roles of different categories of the population, including gender roles and status-role expectations. Based on the time-series analysis female ratio in the ICT organizations was calculated. It allowed to consider the real picture of the development of the analyzed sector with all the changes taking place, as well as to suggest the main priority areas that will promote the active entry of women into the digital economy. The study concluded that, despite the fact that the average number of female employees in ICT organizations is increasing, there is still a significant gender gap among those employed in the sector considered, which indicates that the potential of women in overcoming the acute shortage of IT professionals is not used. It has been established that reducing the digital gender gap in employment is not an end in itself, but the need to make greater use of the labor and intellectual potential of the entire employed population of the country - not only men, but also women. At the same time, the active involvement of women in the digital sector will increase the level of their professional activity and ensure their full participation in the modern labor market.
\end{abstract}

\section{Introduction}

Under current conditions, ICT affect all spheres of modern society, including gender relations. At the same time, digitalization not only opens up new opportunities, but also creates new social challenges and risks. One of the most likely social groups of risks associated with the development of the digital economy is the growth of gender inequality in the workplace and in society as a whole.

Problem of gender inequality is relevant because of the significant changes in modern society, in particular the rethinking of the roles of different categories of the population, including gender roles and status-role expectations. Despite the fact that in most countries of the world women have become more successful than before, the gender gap in society

\footnotetext{
*Corresponding author: pea.znu@mail.ru
} 
today occupies a substantial place among the significant problems of our time. For example, on the labor market today there is a phenomenon of gender inequality associated with "discrimination at the level of preferences", in other words, employers have stereotypes about certain social groups in the hiring process. It is a proven fact that male employers prefer to hire men, and against women they have a number of prejudicestereotypes.

In this study, gender inequality will be understood as a certain characteristic of the social order, in which it is accepted to distinguish two different social groups (men and women), which will have significant differences and accordingly unequal opportunities in the social environment.

ICT provide both new forms of employment and the emergence of new professions. The use of new digital technologies, robotics, artificial intelligence, nanotechnology and biotechnology, genetics, 3D-printing lead to asymmetrical changes in the modern labor market: new professions are emerging, while a number of traditional professions become a past, leading to job cuts. These changes concern, first of all, "female" professions.

At the same time, the so-called STEM professions, namely those related to science, technology, and engineering, are developing rapidly, but there is a gender asymmetry in this sphere as well. In turn, there is a certain increase in the share of women in the ICT sector, as they tend to work with texts and consulting, and men tend to programming. So positions such as operator, content manager, consultant, etc. are predominantly held by women, while men are engaged in programming and developing process architecture.

In the digital economy there is a tendency to smoothing gender inequality, but in this case a comprehensive approach is needed: the impact on the socio-cultural context and the smoothing of stereotypes, vocational guidance for women, attracting them to obtain technical or IT education, strengthening the legal framework and level of social protection, motivation to obtain new knowledge, skills and abilities in the application of digital network technologies, introduction and use of new forms of employment.

The study of the causes and social mechanisms of the emergence and reproduction of gender asymmetry in different spheres of modern Russian society, aimed at finding ways to eliminate them, is relevant to the achievement of the goals of sustainable development of Russia.

Currently, gender inequality remains one of the most urgent problems under consideration of domestic and foreign scholars in various fields. Current theories are based on the process of forming gender relations (doing gender) or the formation of gender boundaries between the sexes.

For example, representatives of the Institute of Social and Economic Studies of Population, RAS together with scientists of the Institute of Socio-Political Research, RAS conducted a gender analysis of new challenges and risks in the labor sphere faced by modern Russian society, investigated the consequences of increasing labor market flexibility and digitalization of economy for women and men, gave special place to the gender research methodology [1].

The authors from Peoples' Friendship University of Russia revealed the historical roots of gender asymmetry in labor and employment spheres and described the current state of the problem. They established that gender discrimination in Russia is a result of existing social norms and rules that reproduced unequal relations between men and women [2.].

Researchers representing Market Economy Institute of the Russian Academy of Sciences, MEI RAS and Autonomous Non-Commercial Organization for Higher Education "Institute of Business Career" analyzed the scope of gender inequality in professional activities in the Russian socioeconomic space, identified features and trends of changing gender boundaries in the context of labor relations in the era of global digitalization [3]. 
Researchers from the State University - Higher School of Economics identified the causes of gender segregation and its impact on the labor performance of major categories of workers within the domestic labor market using a unique database on the personnel of industrial enterprises, found that differences in the trajectories of intra-firm labor mobility of men and women lead to the formation and consolidation of segregated employment structures [4].

In her turn, Efimova V. analyzed the main forms of manifestations and factors of gender discrimination in the Russian labor market, described the role of traditional gender stereotypes, paid attention to intra-firm discrimination against women, especially the problem of the "glass ceiling" [5].

Representatives of the University of Paderborn conducted a systematic analysis of the relationship between the gender characteristics of the main categories of employees and the digitalization by creating a conceptual heuristic, characterized horizontal and vertical gender segregation in the modern labor market. The researchers are convinced that the formation of gender and basic patterns of division of labor are directly related to the digitalization, which needs further research [6].

In turn, Martin Hilbert, from the University of Southern California (USC), Annenberg School for Communication, United States, analyzed the digital gender inequality, as well as the technological opportunities for women in developing countries. He found that digital technology is one of the main tools to improve living standards and living conditions, and to address key gender issues related to increasing employment in the labor market [7].

Scientists of the Institute of Informatics \& Telecommunications, N.C.S.R. "Demokritos" (Greece): Pappas M., Drigas A., Papagerasimou Ya., Dimitriou H., Katsanou N., Papakonstantinou S., Karabatzaki Z. studied the impact of ICT on the possibility of effective employment and entrepreneurship development for women, using the Greek example. Using a questionnaire method, they established the relevance of developing priority areas to promote women's active participation as entrepreneurs and main categories of employees in the ICT sector, as well as in other economic activities, using the possibilities of ICT [8].

A joint study by representatives of the Centro de Investigación y Docencia Económicas (Judith M., Mayne G.), Tandem Research (Aneja U.), Kiel Institute for the World Economy, Institute of Labor Economics (Sorgner A.) on overcoming the gender digital inequality allowed the authors to actualize the need to assess the global gender gap and develop meaningful indicators aimed at reducing the gender gap in digital integration, which will empower women while reducing gender inequality in the labor market and improve their financial situation [9].

Representatives of the European Trade Union Confederation (Belgium) took into account the peculiarities of digitalization, automation, and technological change in the current development context. A gendered approach to digitalization has been developed, suggesting areas in which digitalization has had a noticeable impact on employment: employment structure (including career change and job content), and forms of work (including labor relations and work organization) that promote equal access to quality work for men and women [10].

The special importance of the studied phenomenon is also indicated by the reports of the World Economic Forum, the calculation of the Gender Inequality Index, the focus of world policy on the process of leveling of gender inequality.

For the Russian Federation such a course is outlined in such normative acts as the program "Digital Economy of the Russian Federation for 2017-2030" [11], "National Strategy of Actions for Women for 2017-2022", in which the problems of insufficient integration of women in the labor market, which is associated primarily with innovations in technology, are outlined[12]. 
The socio-economic policy of the state is aimed at training modern professionals who can freely navigate the digital environment, understand how and when to use innovative ICT in professional activities and in everyday reality. Possessing competencies in the use of digital technology is a prerequisite for personal and professional development of an individual, regardless of gender.

\section{Methodology}

In the study, the time-series analysis was applied to assess female ratio in the ICT organizations. This coefficient shows number of women per 1,000 employees in the organizations. The main indicators of dynamics are presented and calculated on the basis of variable (chain) base, which reflects the cyclic development of the coefficient and makes it possible to identify possible growth reserves, and constant (basic) base, which allows tracing the increase (or decrease) of the coefficient in comparison with the initial period. Analysis of the dynamics of the female ratio in the ICT organizations makes it possible to consider the real picture of the ICT sector development with all the changes taking place, as well as to plan its perspectives.

\section{Results}

In the Russian Federation, the ICT sector is traditionally among the "male" types of activities. In recent years there have been radical changes in the organizational and personnel structure of such activities as communications and information technology (IT), so that the predominance of male employees in them has increased. In turn, the issue of increasing the presence of women in the ICT sector by increasing the demand for ICT specialists (in Russia the percentage of ICT specialists in the total number of employed workers is about 3\%) deserves attention from the standpoint of the development of the analyzed sector, as well as in the context of expanding opportunities for women and strengthening their socio-economic positions. The solution of these problems has been put forward by public authorities as one of the main goals of the development of a modern digital society.

Figure 1 provides information on the structure of key ICT professionals by skill level in 2019, taking into account the gender structure [13].

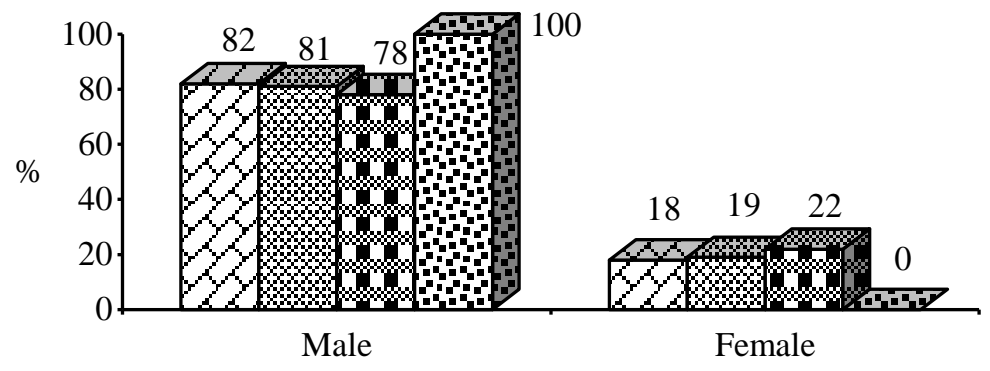

\Heads of services and departments in ICT sector
ICT specialists of the top-level of qualification
ICT specialists of the mid-level of qualification
Q Qualified workers

Fig. 1. Structure of main ICT specialists by qualification level with regard to gender structure, $\%$. 
The data in the figure show that there is a significant gender gap in the structure of key specialists: among managers, in particular, among heads of ICT services and units, in 4.6 times; among top-level ICT specialists (ICT specialists, software and application developers and analysts, database specialists, graphic and multimedia designers, ICT sales specialists, etc.) in 4.3 times, among mid-level ICT specialists (ICT technicians, ICT operation technicians, ICT support technicians, etc.), in 3.5 times. There were no female employees among qualified workers (installers and repairmen of electronic and telecommunication equipment) [13].

Analyzing the contribution of women to the development of the ICT sector [14], let us pay attention to such an indicator as the number of people employed in ICT organizations (fig. 2).

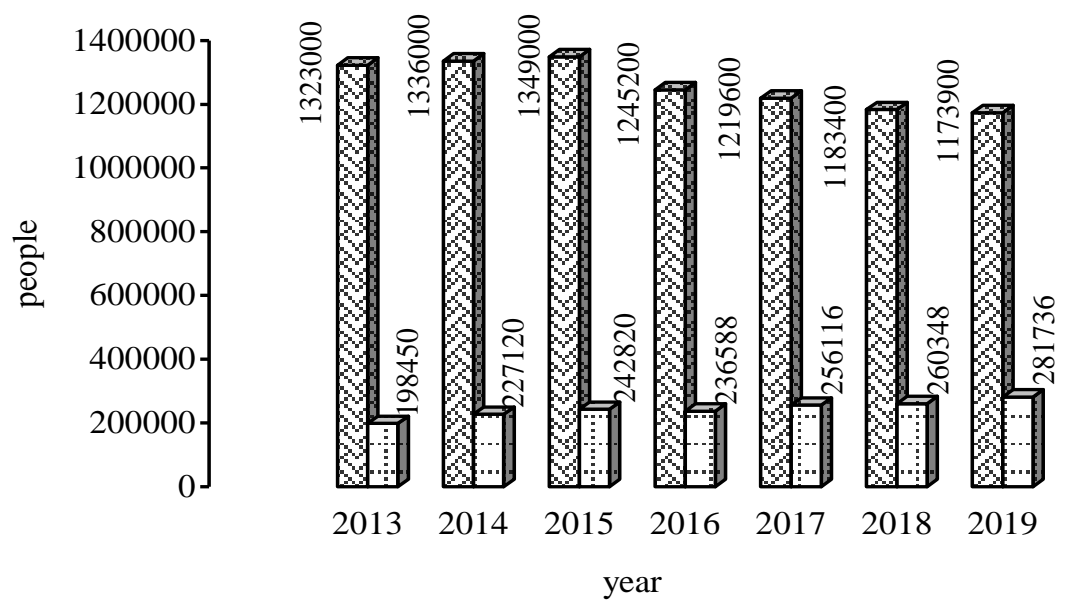

Average number of employees in ICT organizations, people

Average number of female employees in ICT organizations, pe

Fig. 2. Average number of employees in ICT organizations, people.

The analysis of Figure 2 allowed us to conclude that over the period considered there was a decrease in the average number of employees in organizations of ICT sector by 149100 people, a sharp decrease was observed in 2016 by 103800 people compared to the previous period.

At the same time, $19.3 \%$ of the total average number of employees was women, whose number increased by 83286 employees during the study period.

Based on the data presented (Fig. 2), the female ratio in the ICT organizations was calculated, which makes it possible to assess the impact of ICT on the development of women's professional activity (Table 1).

Table 1. Dynamics of the female ratio in the ICT organizations.

\begin{tabular}{|c|c|c|c|c|c|c|c|c|}
\hline \multirow{2}{*}{\multicolumn{2}{|c|}{ Indicator }} & \multicolumn{7}{|c|}{ Year } \\
\hline & & 2013 & 2014 & 2015 & 2016 & 2017 & 2018 & 2019 \\
\hline \multicolumn{2}{|c|}{ Female ratio } & 150 & 170 & 180 & 190 & 210 & 220 & 240 \\
\hline \multicolumn{9}{|c|}{ Dynamics of female ratio in the ICT organizations } \\
\hline \multirow{2}{*}{$\begin{array}{l}\text { Absolute } \\
\text { increase }\end{array}$} & chain & - & 20 & 10 & 10 & 20 & 10 & 20 \\
\hline & basic & - & 20 & 30 & 40 & 60 & 70 & 90 \\
\hline \multirow{2}{*}{$\begin{array}{c}\text { Growth } \\
\text { coefficient }\end{array}$} & chain & - & 1,13 & 1,06 & 1,06 & 1,1 & 1,05 & 1,09 \\
\hline & basic & - & 1,13 & 1,2 & 1,26 & 1,4 & 1,47 & 1,6 \\
\hline \multirow{2}{*}{$\begin{array}{l}\text { Growth } \\
\text { rate, \% }\end{array}$} & chain & - & 113 & 106 & 106 & 110 & 105 & 109 \\
\hline & basic & - & 113 & 120 & 126 & 140 & 147 & 160 \\
\hline
\end{tabular}




\begin{tabular}{|c|c|c|c|c|c|c|c|c|}
\hline $\begin{array}{c}\text { Increase } \\
\text { rate, \% }\end{array}$ & chain & - & 13 & 6 & 6 & 10 & 5 & 9 \\
\cline { 2 - 9 } & basic & - & 13 & 20 & 20 & 40 & 47 & 60 \\
\hline $\begin{array}{c}\text { Absolute } \\
\text { value of } \\
\text { one percent } \\
\text { increase }\end{array}$ & chain & - & 1,7 & 1,8 & 1,9 & 2,1 & 2,2 & 2,4 \\
\cline { 2 - 9 } & basic & - & 1,5 & 1,5 & 1,5 & 1,5 & 1,5 & 1,5 \\
\hline
\end{tabular}

\section{Discussion}

The calculations conducted allow us to conclude that the maximum increase in the chain absolute increase was observed in 2014, 2017, and 2019 and was 20 female employees. In 2015, 2016 and 2018, this indicator was lowest. This indicates a sharp decrease in the number of women in the ICT organizations, which is directly related to the ongoing digitalization.

According to the basic indicators for the period under study, we can conclude that the female ratio in the ICT organizations has increased by 10-20 units compared to 2013.

In turn, the maximum chain growth rate of the female ratio and its corresponding increase rate were observed in 2014 and were to $113 \%$ and $13 \%$, respectively.

The minimum values of the indicators under consideration were found in 2018 and were $105 \%$ and $5 \%$, which is associated with a reduction in the number of women in the organizations of the studied sector in this period, compared with the previous one.

The maximum basic growth rate was reached in 2019 at $160 \%$. The obtained result means that the number of female employees in the ICT organizations in the Russian Federation increased by 1.6 times compared to 2013. The minimum values of this indicator were obtained in 2013 at the level of $113 \%$ and $13 \%$, which is associated primarily with the reduction in the number of organizations of the sector under study in comparison with the base period.

The study concludes that, despite the fact that the average number of female employees in the ICT sector is increasing, there is still a significant gender gap among those employed in this sector, which indicates that the potential of women is not used in overcoming the acute shortage of IT-sector professionals observed in the development of the digital economy.

\section{Conclusion}

Russian women actively use ICT in their daily activities (online information resources for communication, obtaining electronic content, searching for information, electronic purchases): the proportion of Internet users among them is almost the same as among men (77\% and $72 \%$, respectively).

However, for the further successful development of Russia's digital economy, it is necessary for information technology to be mastered not only by selected specialists, but also by a broad mass of workers of different professions, not only men, but also women. Involving women in STEM employment is not an end in itself, but an economic necessity.

Among the priority areas that will facilitate the entry of women into the digital economy, it is proposed to include:

- coordinated and effective economic and social policy, the priority of which should be to counteract gender inequality and insecurity as satellites of technological change;

- bringing Russian labor law into line with the new realities of the labor market by revising outdated norms and introducing new ones; 
- development and implementation at all levels of the Russian economy (state, regional, corporate) of programs aimed at more effective involvement of women in the digital economy;

- $\quad$ ensuring symmetrical norms of labor law for women and men (with the exception of issues of maternity protection);

- improving the quality of the education system so that it meets the demands and realities of a rapidly changing economy; developing and implementing national and regional programs to increase the involvement of women in STEM professions;

- improving the collection and analysis of gender statistics, comparing statistics on education and employment of women and men in the field of technology; monitoring compliance with labor rights and equality of treatment in the workplace, and creating conditions for women and men to combine family life and work;

- awareness-raising work on gender equality issues, aimed at overcoming gender stereotypes about the role of women in society, etc.

Involving women in the information and communication technology sector will not only ensure their full participation in modern society, but will also stimulate state economy.

Reducing the digital gender gap in employment is not an end in itself, but the need to make greater use of the labor and intellectual potential of the entire employed population not only men, but also women. The active involvement of women in the digital sector will increase the level of their professional activity and ensure their full participation in the modern labor market.

\section{References}

1. Z. Khotkina, V. Dobrokhleb, N. Rusanova, Popul, 4, 14 (2018)

2. M. Burchakova, V. Khozhempo, RUDN J. E, 1, 9 (2015)

3. M. Dudin, E. Levina, A. Anishchenko, Soc. and lab. R, 38, 11 (2020)

4. I. Maltseva, D. Nesterova, Vest. Vor. Gos. Un. E, 1, 11 (2011)

5. V. Yefimova, Bul. of the IE RAS, 5, 8 (2013)

6. B. Kohlrausch, L. Weber, Gen. and Res, 21, 18 (2020)

7. M. Hilbert, Elsev, 34, 10 (2011)

8. M. Pappas, A. Drigas, Ya. Papagerasimou, H. Dimitriou, N. Katsanou, S. Papakonstantinou, Z. Karabatzaki, J. Open Innov. Techn. Mark. Complex, 4, 15 (2018)

9. M. Judith, G. Mayne, U. Aneja, A. Sorgner, Open-Asses. E. J, 13, 12 (2019)

10. A. Piasna, J. Drahokoupil, Transf, 2 (2017)

11. The National Program "Digital Economy of the Russian Federation" July 28, № 1632-r (2017)

12. National Strategy of Actions for Women for 2017-2022 March 08, № 410-r (2017)

13. G. Abdrakhmanova, K. Vishnevskiy, L. Gokhberg, Digital Economy Indicators in the Russian Federation (NAU HSE, Moscow, 2019)

14. G. Abdrakhmanova, L. Gokhberg, M. Kevesh, Digital Economy Indicators in the Russian Federation (NAU HSE, Moscow, 2017) 